\title{
Simulasi Penerapan Metode Decision Tree (C4.5) Pada Penentuan Status Gizi Balita
}

\author{
Annas Prasetio ${ }^{1}$, Muhammad Hari Hasibuan ${ }^{2}$, Primatua Sitompul ${ }^{3}$ \\ 1,2,3 Magister Ilmu Komputer, Universitas Potensi Utama Medan \\ J1. KL Yos Sudarso KM 6.5 No. 3 A, Tanjung Mulia, Medan Deli, 20241 \\ Corresponding author's e-mail: annasprasetio45@gmail.com
}

\begin{abstract}
Abstrak - Permasalahan yang terjadi di Indonesia sampai saat ini adalah permasalahan mengenai kesehatan, seperti masalah yang terjadi pada kesehatan gizi balita salah satunya. Banyak balita yang mengalami gangguan kesehatan yang dapat menjadi pemicu pada status gizi. Hal ini menjadi perhatian serius bagi negara dan khususnya para orang tua. Adapun cara menentukan Status gizi pada balita dapat dinilai dengan mengukur tubuh balita berdasarkan umur, tinggi dan berat badannya. Untuk dapat mengetahui status gizi pada balita. Penelitian ini menggunakan data sebanyak 123 data dengan kelahiran balita dari 2015 sampai 2019. Tujuan penelitian ini untuk mengetahui pohon keputusan berdasarkan data yang ada untuk dianalisa kesesuainnya dan dilakukan klasifikasi. Hasil uji coba menunjukkan terdapat kesesuain Decision Tree dengan data yang ada. Algoritma C45 memberikan akurasi yang lebih baik karena algoritma C4.5 membangun pohon dengan jumlah cabang tiap simpul sesuai dengan nilai simpul tersebut. Dengan demikian dapat disimpulkan bahwa algoritma C4.5 mampu mengklasifikasikan status gizi balita.
\end{abstract}

Kata kunci: Status Gizi, Decision Tree, Algoritma C4.5.

\section{Pendahuluan}

Permasalahan yang terjadi di Indonesia sampai saat ini adalah permasalahan mengenai kesehatan, seperti masalah yang terjadi pada kesehatan gizi balita salah satunya. Banyak balita yang mengalami gangguan kesehatan yang dapat menjadi pemicu pada status gizi. Hal ini menjadi perhatian serius bagi negara dan khususnya para orang tua. Adapun cara menentukan Status gizi pada balita dapat dinilai dengan mengukur tubuh balita berdasarkan umur, tinggi dan berat badannya. Untuk dapat mengetahui status gizi pada balita. Penelitian ini menggunakan data sebanyak 123 data dengan kelahiran balita dari 2015 sampai 2019.

Untuk membantu masyarakat dalam pengenalan penyakit gizi buruk, banyak penelitian - penelitian yang telah dilakukan sebelumnya. Diantaranya adalah "Diagnosa Gangguan Gizi Menggunakan Metode Certainty Factor"'[1]. Tujuan penelitian tersebut yaitu untuk memanfaatkan system pakar dalam dunia kesehatan yaitu tentang gizi. Penelitian lainnya oleh Lumban Batu \& Novriyeni dengan judul "Sistem Pakar Mendiagnosa Gizi Buruk Pada Balita Dengan Metode Fuzzy Logic”[2]. Penelitian tersebut menerapkan Fuzzy Logic untuk menghitung nilai derajat keanggotaan dengan elemen-elemen variable gizi Hasilnya diperoleh adalah sistem pakar yang mampu berperan untuk menentukan status gizi buruk.

Tujuan penelitian ini untuk mengetahui pohon keputusan berdasarkan data yang ada untuk dianalisa kesesuainnya dan dilakukan klasifikasi. Hasil uji coba menunjukkan terdapat kesesuain Decision Tree dengan data yang ada. Algoritma C45 memberikan akurasi yang lebih baik karena algoritma C4.5 membangun pohon dengan jumlah cabang tiap simpul sesuai dengan nilai simpul tersebut. Dengan demikian dapat disimpulkan bahwa algoritma C4.5 mampu mengklasifikasikan status gizi balita.

\section{Tinjauan Pustaka}

2.1. Gizi

Gizi adalah suatu proses organisme menggunakan makanan yang dikonsumsi secara normal melalui proses digesti, absorpsi, transportasi, penyimpanan, metabolisme dan pengeluaran zat-zat yang tidak digunakan untuk mempertahakan kehidupan, pertumbuhan dan fungsi normal dari organ-organ, serta menghasilkan energi. Kata gizi merupakan kata yang relatif baru dikenal sekitar tahun 1857. Kata gizi berasal dari Bahasa Arab ghidza yang berarti makanan. Dalam Bahasa Inggris, food menyatakan makanan, pangan, bahan makanan [3].

Gizi seimbang adalah susunan pangan sehari-hari yang mengandung zat gizi dalam jenis dan jumlah yang sesuai dengan kebutuhan tubuh, dengan memperhatikan prinsip keanekaragaman pangan, aktivitas fisik, perilaku hidup bersih dan mempertahankan berat badan normal untuk mencegah masalah gizi [4]. Keinginan untuk makan dan kebutuhan pangan menjadi sebuah naluri bagi makhluk hidup yang mendorongnya untuk melakukan berbagai cara dan berusaha mendapatkannya dari alam. Dalam pengertian sederhana seperti ini, 
ukuran tercukupinya kebutuhan pangan dinyatakan dengan kondisi tidak lapar. Setiap makhluk hidup di dunia ini, termasuk manusia memerlukan makanan. Karena setiap hari manusia memerlukan energi. Energi yang dibutuhkan manusia terkandung di dalam makanan. Oleh karena itu, manusia harus mengetahui tentang gizi. Gizi Seimbang adalah makanan yang dikonsumsi oleh seseorang sehari-hari yang beraneka ragam dan memenuhi 5 kelompok zat gizi dalam jumlah yang cukup, tidak berlebihan dan tidak kekurangan [5].

2.2. Klasifikasi

Klasifikasi adalah suatu kegiatan mengelempokkan. Dimana klasifikasi sangat dibutuhkan dalam peprustakaan, karena klasifikasi bertujuan untuk mengelompokkan satu koleksi yang sejenis, yang pengelompokkannya berdasarkan judul, pengarang, dan lain sebagainya [6]. Klasifikasi adalah pengelompokkan yang sistematis pada sejumlah objek, gagasan, buku atau benda-benda lain ke dalam kelas atau golongan tertentu berdasarkan ciriciri yang sama.

\subsection{Algoritma C4.5}

Algoritma C4.5 merupakan pengembangan dari ID3. Beberapa pengembangan yang dilakukan C4.5 adalah bisa mengatasi missing value, continue data dan pruning. Algoritma C4.5 mempunyai input berupa training samples dan samples, training samples berupa data contoh yang akan digunakan untuk membangun sebuah tree yang telah diuji kebenarannya, sedangkan samples merupakan field-field data yang nantinya akan kita gunakan sebagai parameter dalam melakukan klasifikasi data [7]. Dan mereka juga dapat diekspresikan dalam bentukbahasa basis data seperti Structured Query Language untuk mencari record pada kategori tertentu. Cara algoritma $\mathrm{C} 4.5$ untuk membangun pohon keputusan yaitu:

a. Pilih atribut yang akan digunakan sebagai akar.

b. Buatlah sebuah cabang untuk setiap nilai.

c. Bagilah kasus dalam sebuah cabang.

d. Ulangi proses untuk setiap cabang sampai semua kasus pada cabang memiliki kelas yang sama.

2.4 Pohon Keputusan

Decision tree adalah struktur flowchart yang mempunyai tree (pohon), dimana setiap simpul internal menandakan suatu tes atribut, setiap cabang merepresentasikan hasil tes, dan simpul daun merepresentasikan kelas atau distribusi kelas [8]. Alur pada decision tree ditelusuri dari simpul ke akar ke simpul daun yang memegang prediksi kelas. Decision tree adalah salah satu metode yang digunakan untuk pengklasifikasian dan prediksi karena memiliki kemudahan dalam interpretasi hasil [9].

\section{Metode Penelitian}

Bagian ini menggambarkan bagaimana kerangka penelitian yang dilakukan agar sesuai dengan tujuan dan hasil yang diinginkan dengan waktu yang efisien. Adapun kerangka penelitian dapat dilihat pada gambar berikut:

\section{Hasil dan Pembahasan}

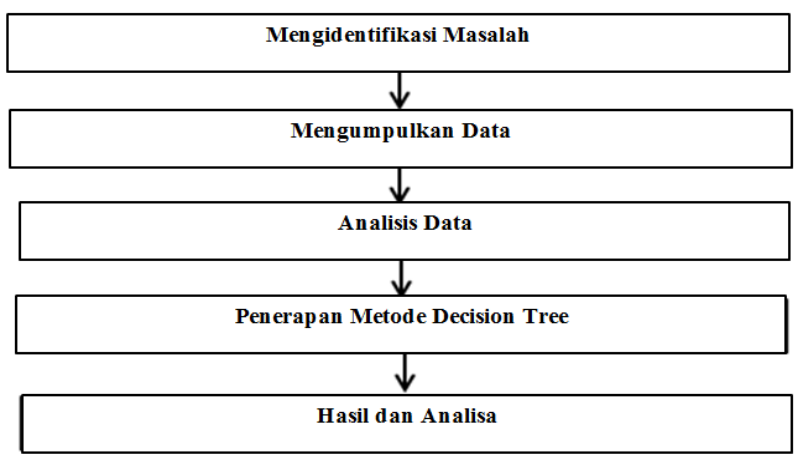

Gambar 1. Kerangka Kerja Penelitian

Langkah-langkah penyelesaiannya:

1. Berikut sampel data penelitian yang dipakai:

Kriteria yang dipakai adalah tinggi badan dan berat badan 
Vol. 4 No. 3, Juni 2021

P-ISSN 2620-8342

E-ISSN 2621-3052

\begin{tabular}{|c|c|c|c|c|c|c|c|c|c|}
\hline No & NIK & Nama & Berat & Tinggi & BBIU & ZS BBIU & TBIU & ZS TBIU & BВ \\
\hline 1 & 120731180316000 & MUHAMMMAD ALLIF PRATAMMA & 14 & 96 & Berat Badan Normal & -1.04 & Normal & -1.46 & Gizi Baik \\
\hline 2 & 120731560518000 & kiara maysa putri & 10 & 78 & Berat Badan Normal & -0.47 & Normal & -1.24 & Gizi Baik \\
\hline & 120731160616000 & Gäbriel & 13 & 95 & Berat Badan Normal & -1.41 & Normal & -1.32 & Gizi Baik \\
\hline & 121210660417000 & FITRICHOIRUINISQ & 11.2 & 86 & \begin{tabular}{|l|} 
Berat Badan Normal \\
\end{tabular} & -1.38 & Normal & -1.89 & Gizi Baik \\
\hline 5 & 1212101610180000 & \begin{tabular}{|l|l|l} 
Dion sipayung \\
\end{tabular} & 9.5 & 76 & Berat Badan Normal & -0.69 & Normal & -1.13 & Gizi Baik \\
\hline 6 & 120731301116000 & Sayudi & 13.5 & 96 & Berat Badan Normal & -1.61 & Normal & -1.89 & Gizi Baik \\
\hline & 120731020318000 & Merryana & 12 & 86 & \begin{tabular}{|l|} 
Berat Badan Normal \\
\end{tabular} & -0.57 & Normal & -1.51 & Gizi Baik \\
\hline & 120731271217000 & verrel hardiansyath & 12.2 & 86 & Berat Badan Normal & -0.01 & Normal & -0.45 & Gizi Baik \\
\hline 9 & 120731080317000 & ALLKHALLIFIZIKRIHAQDY & 13.1 & 92 & Berat Badan Normal & -0.55 & Normal & -0.76 & Gizi Baik \\
\hline 10 & 120731090516000 & m.hafiz alkhallifi & 15.3 & 96 & Berat Badan Normal & -0.19 & \begin{tabular}{|l|l|l|l|l|l|l|} 
Normal \\
\end{tabular} & -1.24 & Gizi Baik \\
\hline 11 & 120732006150001 & \begin{tabular}{|l} 
fatir ramadan \\
\end{tabular} & 14 & 96 & Berat Badan Normal & -0.79 & Normal & -1.05 & Gizi Baik \\
\hline 12 & 120731430916000 & nuralika azzahra & 14 & 95 & Berat Badan Normal & -0.33 & Normal & -0.7 & Gizi Baik \\
\hline$\frac{12}{13}$ & \begin{tabular}{|l|}
12073169005100000 \\
1207310
\end{tabular} & NABDHIRARANURARZZZZAH & $\begin{array}{c}13.5 \\
13.5\end{array}$ & 94 & Berat Badan Normal & $\begin{array}{c}-0.35 \\
-0.9 \\
\end{array}$ & | & -0.42 & 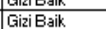 \\
\hline 14 & 120731130915000 & ARDIYAN ONCAT & 13.5 & 34 & Berat Badan Normal & -1.79 & \begin{tabular}{|l|l} 
Pendek \\
\end{tabular} & $\frac{-1.74}{-2.18}$ & Gizi Baik \\
\hline 15 & 120731200014000 & INDRA SETIAWAN & 8.8 & 72 & Berat Badan Normal & -0.45 & Normal & -0.73 & Gizi Baik \\
\hline 16 & 120731650317000 & DIORY & 12.6 & 88 & Berat Badan Normal & -0.82 & Normal & -1.77 & Gizi Baik \\
\hline 17 & 120731461216000 & AQILA VIONA & 12.5 & 92 & Berat Badan Normal & .0 .91 & Normal & -0.97 & Gizi Baik \\
\hline 18 & 120731551214000 & SEKARAYU & 8.9 & 76 & Berat Badan Normal & 0.32 & Normal & 1.65 & Gizi Baik \\
\hline 19 & 120731470516000 & AKIFA,ZAHIRA & 13.5 & 92 & Berat Badan Normal & -0.96 & Normal & & Gizi Baik \\
\hline 20 & 1207313112160001 & AZKA ALASFAR & 12.8 & 88 & Berat Badan Normal & -0.96 & Pendek & -2.21 & Gizi Baik \\
\hline & 120731200021700 & DIMASNUGRAHA & 12.5 & & Berat Badan Normal & & Normal & -1.95 & Gizi Baik \\
\hline$\frac{21}{22}$ & \begin{tabular}{|l|}
1207071200001600 \\
1203100616000
\end{tabular} & 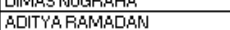 & $\mid \frac{1.5}{15.1}$ & $\frac{86}{96}$ & \begin{tabular}{|l} 
BeracBadan Normal \\
Berat Badan Normal
\end{tabular} & -0.21 & | & $\frac{-1.09}{-1.09}$ & \begin{tabular}{|l|} 
Galibalk \\
Gizi Baik
\end{tabular} \\
\hline 23 & 120731700316000 & YURIDA NINGGIH & 13.7 & 95 & Berat Badan Normal & .0 .96 & 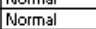 & -1.45 & Gizi Baik \\
\hline & 120731590716000 & SILVA AKTISYAH & 10 & 77 & Berat Badan Normal & -0.12 & Normal & -0.9 & Gizi Baik \\
\hline 25 & 120731100416000 & RAFA GUNAWAN & 12.8 & 94 & Berat Badan Normal & -1.71 & Normal & -1.85 & Gizi Baik \\
\hline 20 & \begin{tabular}{|l|}
1212105706170000 \\
121000
\end{tabular} & NAZRARAMADAN & $\frac{1.68}{11.6}$ & $\frac{34}{85}$ & Berat Badan Normal & -.0 .81 & \begin{tabular}{|l|} 
Normal \\
Normal
\end{tabular} & $\frac{-1.60}{-1.74}$ & 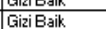 \\
\hline 27 & 121809090717000 & GHALY AHSYAM & $\frac{10.04}{12}$ & 86 & Berat Badan Normal & .0 .87 & Normal & -1.73 & \begin{tabular}{|l|l} 
Gizi Baik \\
\end{tabular} \\
\hline 28 & \begin{tabular}{|l|l|}
12073129111100000 \\
\end{tabular} & NURRABFIZ SARABGGIH & 13.7 & 97 & \begin{tabular}{|l} 
Berat Badan Normal \\
\end{tabular} & -1.49 & Normal & -1.66 & Gizi Baik \\
\hline 29 & 120731681015000 & RISA ANIN DYASW/ARI & 13.5 & 96 & Berat Badan Normal & -1.47 & Normal & -1.84 & Gizi Baik \\
\hline$\frac{23}{30}$ & 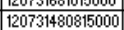 & AZURADAMANIK & $\frac{1.9}{14}$ & 38 & \begin{tabular}{|l} 
Detac Badaninominal \\
Berat Badan Normal
\end{tabular} & $-\frac{1.479}{-1.39}$ & \begin{tabular}{|l|l|l|l|l} 
Normal \\
Normal
\end{tabular} & $\frac{-1.04}{-1.69}$ & \begin{tabular}{|l} 
Galizialk Baik \\
\end{tabular} \\
\hline 31 & 120731610617000 & VIKAHSAPFRIANII & 11.5 & 85 & Berat Badan Normal & -0.87 & Normal & -1.71 & Gizi Baik \\
\hline$\frac{31}{32}$ & 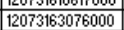 & MUTIARAR SAQBINABH & $\begin{array}{ll}1.3 .2 \\
13.2\end{array}$ & 95 & 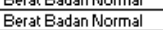 & - -0.92 & Normal & $\frac{-1.61}{-0.93}$ & \begin{tabular}{|l} 
Malizi Baik \\
\end{tabular} \\
\hline 33 & 1207312311170001 & RIO AL-FARIZI & 11.6 & 86 & Berat Badan Normal & -0.6 & Normal & -0.74 & Gizi Baik \\
\hline 34 & 121210290917000 & AHMADAZZAM & 12.2 & 86 & Berat Badan Normal & -0.4 & Normal & -1.17 & Gizi Baik \\
\hline 35 & 120731008160002 & M. SYAPUUTRA PRATAMA & 4 & & Berat Badan Normal & 0.02 & Normal & -1.08 & Gizi Baik \\
\hline
\end{tabular}

Gambar 2. Sampel Penelitian

2. Selanjutnya data tersebut diolah menggunakan Tools Rapid miner untuk membuat pohon keputusan:

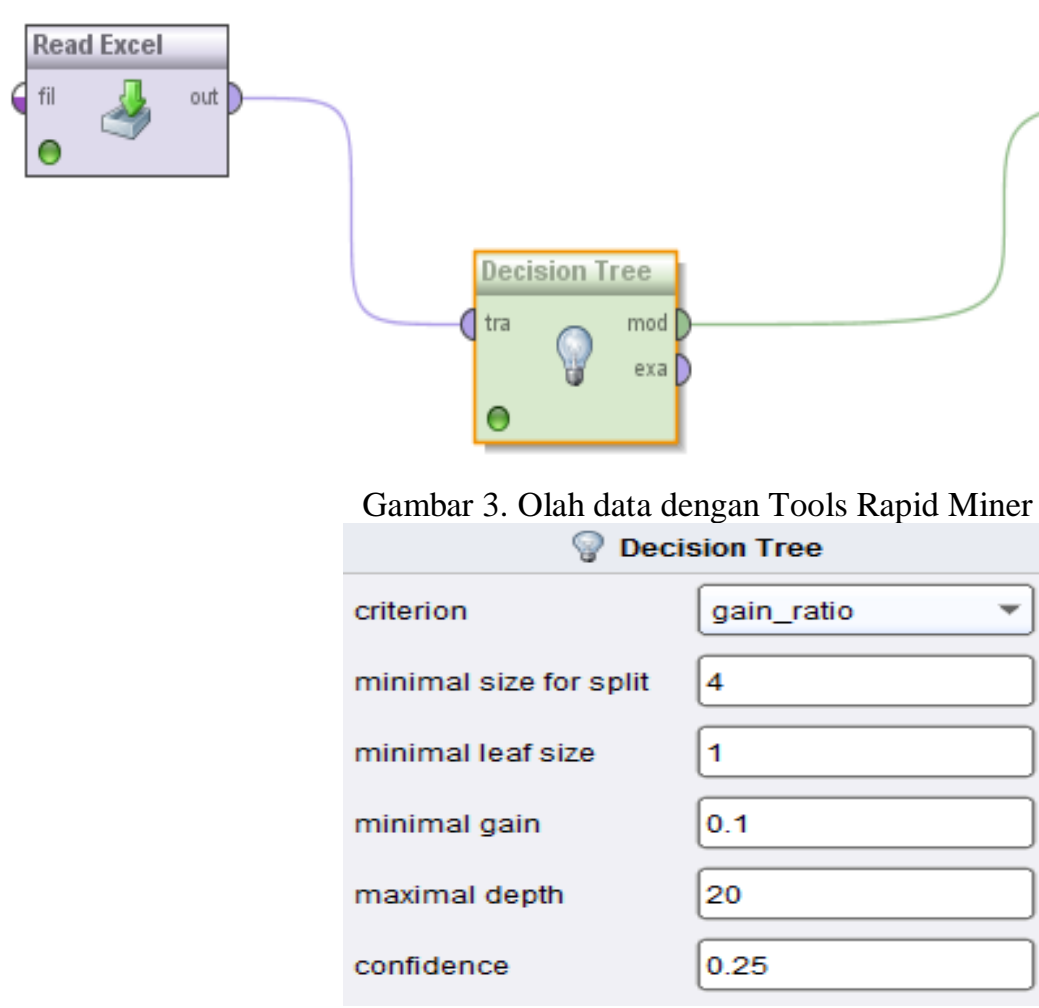

Gambar 4. Olah data dengan Tools Rapid Miner 


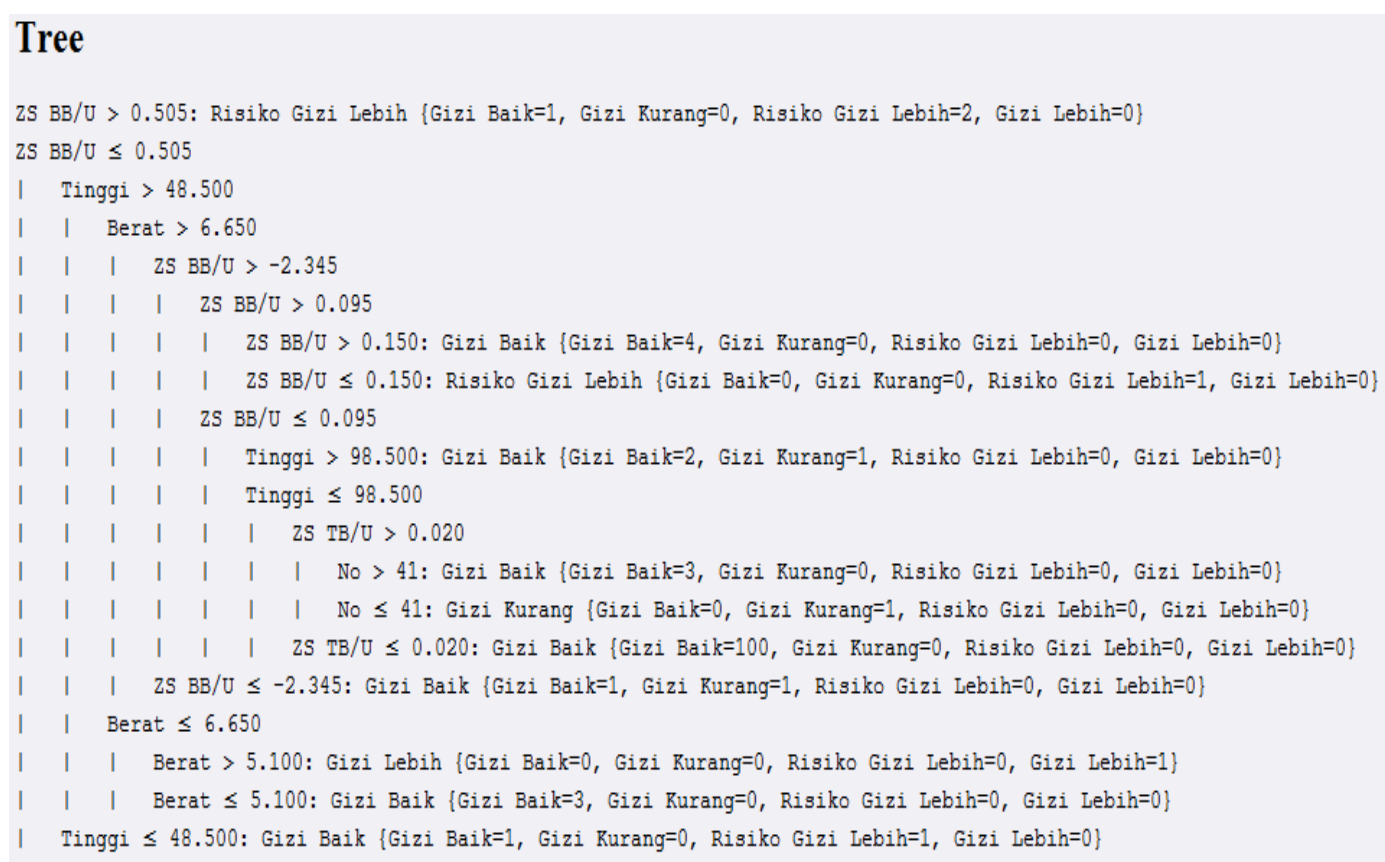

\section{Gambar 5. Olah data dengan Tools Rapid Miner}

3. Sehingga didapatkan Pohon Keputusannya dengan menggunakan Rapidminer:

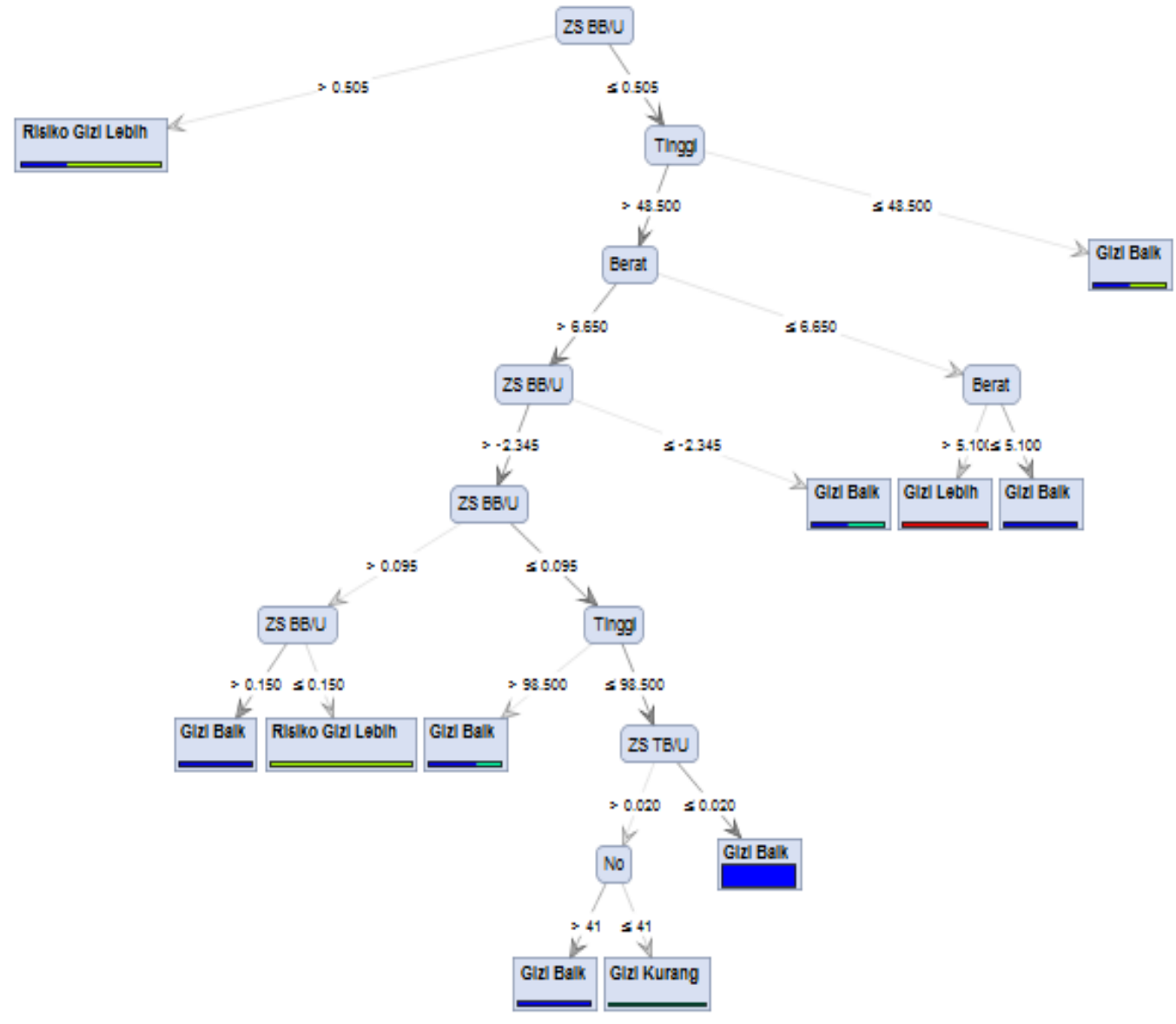


4. Menghitung $\mathrm{C} 4.5$

Gambar 6. Hasil Pohon Keputusan dengan Tools Rapid Miner

$$
\text { Gain }(\mathrm{S}, \mathrm{A})=\text { Entropy }(\mathrm{S})-\sum_{i=1}^{n} \frac{\left|O_{1}\right|}{|S|} * \text { Entropy }(S i)
$$

\section{Keterangan :}

S : Himpunan Kasus

A : Atribut

n : Jumlah Partisi Atribut A

$\left|S_{1}\right| \quad$ : Jumlah kasus pada partisi ke-i

$|S| \quad$ : Jumlah Kasus dalam S

Dan rumus yang kedua adalah:

$$
\operatorname{Entropy}(S)=\sum_{i=1}^{n}\left(-p_{i}\right) * \log _{2} p_{i}
$$

\section{Keterangan : \\ S : Himpunan kasus \\ n : Banyaknya partisi S \\ pi : probabilitas yang didapat dari kasus i dibagi total kasus.

\begin{tabular}{|c|c|c|c|c|c|c|c|c|c|}
\hline ALTERNATIF & KRITERIA & $\begin{array}{l}\text { JMLAH } \\
\text { KASUS }\end{array}$ & $\begin{array}{l}\text { Gizi } \\
\text { Baik } \\
\text { (Sl) }\end{array}$ & $\begin{array}{c}\text { Gizi } \\
\text { Kurang } \\
\text { (S2) }\end{array}$ & $\begin{array}{c}\text { Gizi } \\
\text { Lebih } \\
\text { (S3) }\end{array}$ & ENTROPY & $\begin{array}{l}\text { INFORMATIO } \\
\text { NGAIN }\end{array}$ & $\begin{array}{c}\text { SPLIT } \\
\text { INF0 }\end{array}$ & GAIN RATIO \\
\hline TOTAL & & 123 & 116 & 3 & 4 & 0.100725855 & & & \\
\hline \multirow[t]{4}{*}{ Tinggi Badan } & & & & & & & 0 & $\begin{array}{c}0.60153 \\
6241\end{array}$ & 0 \\
\hline & Normal & 107 & 100 & 3 & 4 & 0 & & & \\
\hline & Pendek & 15 & 14 & 0 & 1 & & & & \\
\hline & $\begin{array}{l}\text { Sangat } \\
\text { Pendek }\end{array}$ & 1 & 1 & 0 & 0 & 0 & & & \\
\hline \multirow[t]{3}{*}{ Berat Badan } & & & & & & & -0.399678922 & $\begin{array}{c}0.41944 \\
132 \\
\end{array}$ & -0.952883997 \\
\hline & Normal & 119 & 112 & 2 & 5 & 0.429071954 & & & \\
\hline & Kurang & 4 & 3 & 1 & 0 & 1.311278124 & & & \\
\hline
\end{tabular} \\ Gambar 7. Rumus C4.5}

Gambar 8. Hasil Keputusan

\section{Kesimpulan}

Berdasarkan hasil penelitian dapat disimpulkan bahwa:

1. Algoritma $\mathrm{C} 4.5$ dapat diterapkan dalam menentukan status gizi balita.

2. Dari 2 atribut antara lain : Berat badan (C1), Tinggi Badan (C2).

3. Dalam hal ini juga kami menguji kebenaran data yang digunakan, apakah metode klasifikasi C4.5 dapat diterapkan pada status gizi balita dengan bantuan software RapidMiner.

4. Hasil perhitungan software RapidMiner menunjukkan akurasi menggunakan tools performance adalah $100 \%$.

5. Penulis bekerja sebagai guru pemrograman komputer dan Analisis.

\section{Daftar Pustaka}

[1] Z. Azmi and M. Dahria, "Decision Tree Berbasis Algoritma Untuk Pengambilan Keputusan," Saintikom, vol. 12, pp. 157-164, 2013, [Online]. Available: http://demo.pohonkeputusan.com/files/DECISION TREE BERBASIS ALGORITMA UNTUK PENGAMBILAN KEPUTUSAN.pdf?i=1.

[2] N. Azwanti, "Algoritma C4.5 Untuk Memprediksi Mahasiswa Yang Mengulang Mata Kuliah (Studi Kasus Di Amik Labuhan Batu)," Simetris J. Tek. Mesin, Elektro dan Ilmu Komput., vol. 9, no. 1, pp. 11 22, 2018, doi: 10.24176/simet.v9i1.1627. 
[3] P. Bidang, K. Sains, Y. Mardi, J. Gajah, M. No, and S. Barat, "Jurnal Edik Informatika Data Mining: Klasifikasi Menggunakan Algoritma C4 . 5 Data mining merupakan bagian dari tahapan proses Knowledge Discovery in Database (KDD ) . Jurnal Edik Informatika."

[4] P. Kasih, "Pemodelan Data Mining Decision Tree Dengan Classification Error Untuk Seleksi Calon Anggota Tim Paduan Suara," Innov. Res. Informatics, vol. 1, no. 2, pp. 63-69, 2019, doi: 10.37058/innovatics.v1i2.918.

[5] S. Kom and M. Kom, "PENERAPAN DECISION TREE UNTUK MENGANALISIS MAHASISWA BARU," vol. 7, no. 1, pp. 8-14, 2016.

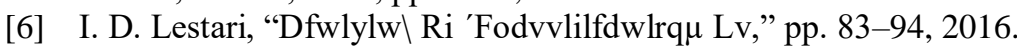

[7] T. Novianti and I. Santosa, "PENENTUAN JADWAL KERJA BERDASARKAN KLASIFIKASI DATA KARYAWAN MENGGUNAKAN METODE DECISION TREE C4.5 (Studi Kasus Universitas Muhammadiyah Surabaya)," J. Komunika J. Komunikasi, Media dan Inform., vol. 5, no. 1, p. 1, 2016, doi: 10.31504/komunika.v5i1.633.

[8] B. I. Saputro, "Penerapan Sistem Klasifikasi Perpustakaan Arkeologi di Perpustakaan Balai Arkeologi Daerah Istimewa Yogyakarta," Berk. Ilmu Perpust. dan Inf., vol. 13, no. 2, p. 107, 2017, doi: 10.22146/bip.23453.

[9] Z. M. Septimar, M. Rustami, and A. Y. . Wibisono, "Jurnal Menara Medika https://jurnal.umsb.ac.id/index.php/menaramedika/index JMM 2020 p-ISSN 2622-657X, e-ISSN 2723 6862," J. Menara Med., vol. 3, no. 1, pp. 66-73, 2020, [Online]. Available: https://www.google.com/url?sa=t\&source=web\&rct=j\&url=https://jurnal.umsb.ac.id/index.php/menara medika/article/view/2199\&ved=2ahUKEwja66i_paDtAhU263MBHdUiAsUQFjAAegQIAxAB\&usg=A OvVaw0bUdEhasRIBe0InxidlHJo. 